\title{
Utilizing a contralateral hamstring autograft facilitates earlier isokinetic and isometric strength recovery after anterior cruciate ligament reconstruction: a randomised controlled trial
}

\author{
Christoffer von Essen ${ }^{1,2} \cdot$ Alexander Hallgren $^{1} \cdot$ Björn Barenius $^{1} \cdot$ Karl Eriksson $^{1}$
}

Received: 24 November 2020 / Accepted: 3 February 2021 / Published online: 18 February 2021

(c) The Author(s) 2021

\begin{abstract}
Purpose To compare muscle strength and patient reported outcomes following ACLR using a semitendinosus (ST) graft from the ipsilateral (IL) leg compared to a graft from the contralateral (CL) leg.

Methods One-hundred and forty patients with an ACL injury were randomized to IL or CL ACLR. Patients were assessed at 6,12 and 24 months with isokinetic and isometric muscle strength measured using Biodex. Patient-reported outcomes and manual stability measurements were also recorded.

Results Patient-related outcomes improved over time for both groups with no significant differences between groups at any time point. No differences between groups in objective knee assessment scores or rerupture rates were found. The IL group was significantly weaker in knee flexion strength at all time points compared to the CL group, additionally the IL group did not recover flexor strength within 2 years.

Conclusion This study demonstrated that utilizing an ST graft harvested from the uninjured limb for ACLR facilitates early isokinetic and isometric strength recovery, with no significant adverse outcomes demonstrated in other measurements and therefore be performed to reduce the risk of long-term strength deficits in the injured leg

Level of evidence II.
\end{abstract}

Keywords ACL $\cdot$ ACL reconstruction $\cdot$ Contralateral $\cdot$ Hamstring

\section{Introduction}

In Sweden, approximately 8000 ACL injuries are reported each year, with approximately 4000 ACL reconstructions performed annually [2]. Although conservative treatment can be successful in the appropriate population, it is less likely to succeed in patients aiming to return to a high level of sporting activity.

The most widely used grafts for reconstruction of the ACL include the patellar tendon (BPTB), hamstring tendon (HS), and quadriceps tendon (QT). Studies comparing

Christoffer von Essen

Christoffer.vonessen@gmail.com

1 Department of Orthopaedics, Stockholm South Hospital, Karolinska Institute, Stockholm, Sweden

2 Capio Artro Clinic, FIFA Medical Centre of Excellence, Sophiahemmet Hospital, Valhallavägen 91, 11486 Stockholm, Sweden outcomes of ACLR with these grafts have not shown one to be clearly superior over the others with regards to knee stability [20, 21, 30, 32]. BTPB grafts have been shown to generate more donor site morbidity than both HT and QT grafts $[1,17,26]$, however, there is no clear consensus regarding which graft achieves the best overall patient outcomes.

In Sweden, a hamstring graft using semitendinosus (ST) is utilized in 95\% of ACLRs, mainly to minimize donor site morbidity [2]. However, it is fair to say that the perfect graft for ACLR does not exist.

There have been studies using BTPB graft from the contralateral noninjured leg for primary ACLR, and in the context of revision surgery, with good results [24, 25]. Additionally, Yasuda [33] performed a study using contralateral semitendinosus-gracilis (ST-G) grafts to distinguish morbidity attributable to graft harvest from the ACLR, and McRae et al. [16] have performed a randomized controlled trial using contralateral ST-G hamstring graft. Neither study identified any significant drawbacks or benefits associated with using an ST-G graft from the unaffected limb. To our 
knowledge, there are no studies assessing the use of an STgraft only.

Studies have shown that the tendon harvest of ST does not compromise function and strength as much as harvesting both ST and G. As such, the technique of harvesting ST whilst preserving gracilis $(\mathrm{G})$ has been recommended [12, 23, 34]. Activity related soreness rarely limits activity and has usually resolved by three months. Furthermore, studies have shown that some regrowth or scar formation of the tendon remnants occurs in a majority of cases [1, 12, 17, 23]. In theory, the use of a graft from the uninjured leg allows the injured limb to avoid additional damage in connection with the ACLR. Another potential advantage may be the early restoration of symmetrical hamstring strength, as a reduced strength ratio (Hamstring/Quadriceps ratio (H/Q)) may be a risk factor for ACL ruptures in females [9].

The objective of this study was to evaluate the outcomes of ACLR using a ST graft harvested from the contralateral leg, compared to ACLR with a ST graft harvested from the ipsilateral leg, in terms of flexion muscle strength and patient-reported outcomes. It was hypothesized that using a CL graft would facilitate earlier strength recovery.

\section{Materials and methods}

The study was approved by the regional ethics committee at the Karolinska Institute, Stockholm Sweden (reference no. 2013/1398-31/2).

Between 2013 and 2017 an orthopedic research team assessed all patients presenting with an isolated ACL deficiency to the orthopedic outpatients clinic. Study eligibility was assessed according to inclusion and exclusion criteria, as listed in Table 1, with 140 of 504 patients deemed eligible, Fig. 1. All eligible patients received standardized information about the trial, orally and in writing, and informed consent was obtained from each patient prior to participation in the study. Randomization with the sealed envelope technique was performed by a research nurse.

Patient demographics including age, gender, injured side, time from injury to surgery and concomitant injuries are

Table 1 Inclusion and exclusion criteria

\begin{tabular}{ll}
\hline Inclusion criteria & Exclusion criteria \\
\hline Unilateral ACL injury & Contralateral ACL injury \\
Age 18-50 years & PCL injury \\
& LCL injury \\
& MCL injury $\geq$ grade 2 \\
& Multiligament injuries \\
& Significant hamstring injury \\
\hline
\end{tabular}

presented in Table 2, with no significant differences between the groups.

Preoperative evaluation included measurements of instrumented laxity using a Rolimeter [6], thigh-circumference $10 \mathrm{~cm}$ proximal to the proximal pole of the patella, as well as a subjective and self-assessed Knee injury and osteoarthritis outcome score (KOOS) [19], IKDC [10], Lysholm score and Tegner activity level [28]. Tegner activity level prior to injury was also recorded. Follow-up examinations were performed at 6, 12, and 24 months postoperatively and included the same scores as preoperatively, as well as a functional strength test assessed with the single-leg hop.

Isokinetic peak torque strength at 60,180 and $300 \%$, and isometric torque strength at $60^{\circ}$, as well as total work in both extension and flexion was measured with Biodex ${ }^{\circledR}$ [27] preoperatively and 6,12 and 24 months postoperatively.

\section{Surgical technique}

All ACLR were performed under general anesthesia by two experienced orthopedic surgeons, and apart from the harvesting site, the surgical procedure was identical for both groups.

After initial diagnostic arthroscopy, the tendons were harvested through a short, anteromedial oblique incision. If the single semitendinosus tendon was not sufficient in length and thickness, the gracilis tendon was harvested as well. The tendons were quadrupled over an adjustable loop Tightrope $^{\mathrm{TM}}$ (Arthrex, Inc., Naples, FL, USA) and armed with nr.2 FibreWire ${ }^{\mathrm{TM}}$ (Arthrex, Inc., Naples, FL, USA). The femoral tunnel was drilled through an anteromedial portal after visualizing the anatomical insertion.

Tibial fixation was achieved by tibial TightRope ABS ${ }^{\mathrm{TM}}$ (Arthrex, Inc., Naples, FL, USA) suture to tension against the button for tibial cortical fixation.

\section{Post-operative management}

The rehabilitation was standardized with full weight bearing allowed from day 1 . Sports activities involving contact or pivoting moments were not permitted for 9 months postoperatively. Patients were permitted to choose rehabilitation center on their own, all familiar with the rehabilitation plan.

\section{Statistical analysis}

Statistical analysis was performed with the IBM SPSS 25.0 software package for Macintosh. Nominal variables were tested by the $\chi^{2}$ test or the Fisher's exact test. Ordinal variables and non-normally distributed interval and scale variables were evaluated by the Mann-Whitney $U$ test, and the Student's $t$ test was used for normally distributed scale variables in independent groups. Longitudinal 


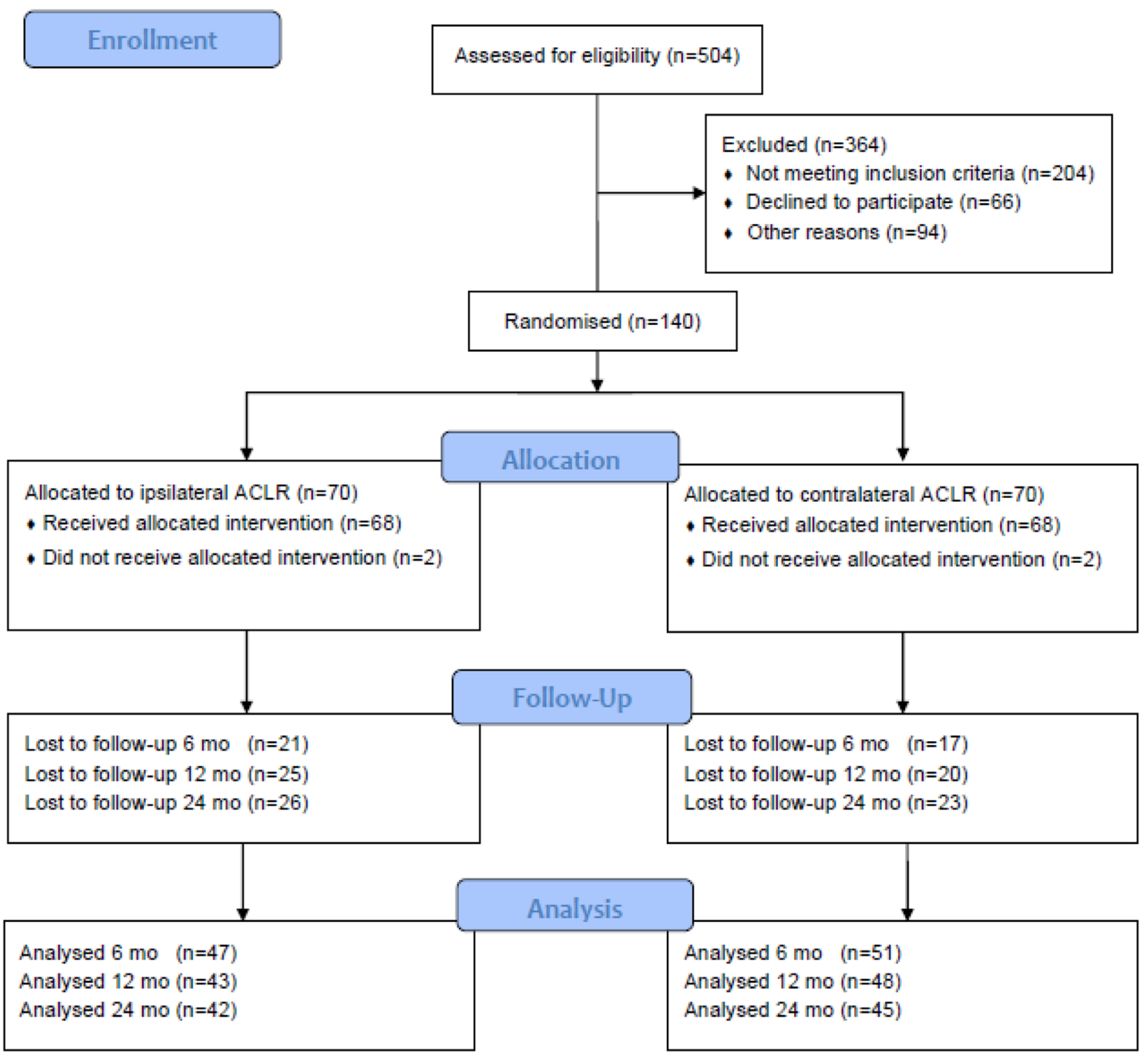

Fig. 1 Enrollment and randomization of subjects

statistics were done with the paired-samples $t$ test for normally distributed scale variables. Results were considered significant at $p<0.05$.

A sample size calculation was performed using the primary endpoint isometric hamstring strength at 6 months. According to this calculation, if the mean difference is $10 \%$ or more and the common within-group standard deviation is 15 , a sample size of 37 patients for the two groups will have a power of $80 \%$ to yield a statistically significant result with $5 \%$ risk of a type-one error.

\section{Results}

\section{Demographics}

Baseline demographics are presented in Table 3. The mean age of the study participants was $33.1 \pm 9$ years, with $58 \%$ male and $42 \%$ female patients. There were no significant differences in age, sex or additional injuries. 
Table 2 Descriptive study population

\begin{tabular}{|c|c|c|c|c|}
\hline & Total $(n=137)$ & $\begin{array}{l}\text { Ipsilateral } \\
\text { ACLR, } n=68\end{array}$ & $\begin{array}{l}\text { Contralateral } \\
\text { ACLR, } n=69\end{array}$ & $P$ value \\
\hline Age at inclusion, mean \pm SD & $33.1 \pm 9$ & $33 \pm 9$ & $31.1 \pm 9$ & n.s \\
\hline Gender: female, $n(\%)$ & $58(42)$ & $33(48)$ & $25(38)$ & n.s \\
\hline $\mathrm{BMI}$ mean $\pm \mathrm{SD}$ & $25 \pm 3$ & $25 \pm 4$ & $25 \pm 3$ & n.s \\
\hline Type of activity when injured $n(\%)$ & & & & n.s \\
\hline Not specified & $39(28)$ & $15(22)$ & $24(35)$ & \\
\hline Soccer & $32(23)$ & $15(22)$ & $17(25)$ & \\
\hline Alpine ski/snowboard & $18(13)$ & $11(16)$ & $7(10)$ & \\
\hline Indoor floorball & $8(6)$ & $4(6)$ & $4(6)$ & \\
\hline MMA (mixed martial arts) & $6(4)$ & $3(4)$ & $3(4)$ & \\
\hline Basketball & $5(4)$ & $2(3)$ & $3(4)$ & \\
\hline Handball & $3(2)$ & $1(1)$ & $2(3)$ & \\
\hline Badminton & $3(2)$ & $2(3)$ & $1(1)$ & \\
\hline Work-related injury & $3(2)$ & $2(3)$ & $1(1)$ & \\
\hline Am. Football & $2(1)$ & $1(1)$ & $1(1)$ & \\
\hline Bandy & $2(1)$ & $1(1)$ & $1(1)$ & \\
\hline Dance & $2(1)$ & $1(1)$ & $1(1)$ & \\
\hline Gym & $2(1)$ & $1(1)$ & $1(1)$ & \\
\hline Gymnastics & $2(1)$ & $2(3)$ & 0 & \\
\hline Slipped on ice & $2(1)$ & $2(3)$ & 0 & \\
\hline Horseback riding & $2(1)$ & 0 & $2(3)$ & \\
\hline Beach volley ball & $1(1)$ & 0 & $1(1)$ & \\
\hline Ice hockey & $1(1)$ & 0 & $1(1)$ & \\
\hline Table tennis & $1(1)$ & 0 & $1(1)$ & \\
\hline Trampoline & $1(1)$ & 0 & $1(1)$ & \\
\hline Wakeboard & $1(1)$ & 0 & $1(1)$ & \\
\hline Traffic accident & $1(1)$ & 0 & $1(1)$ & \\
\hline
\end{tabular}

Patient demographics at baseline for patients with an ACL tear are displayed as mean $\pm \mathrm{SD}$, number and percentage, respectively
Table 3 Demographics

\begin{tabular}{lllll}
\hline & & $\begin{array}{l}\text { Ipsilateral } \\
\text { ACLR } \\
(n=68)\end{array}$ & $\begin{array}{l}\text { Contralat- } \\
\text { eral ACLR } \\
(n=69)\end{array}$ & $p$ value \\
\hline Time injury-recon & $d \pm \mathrm{SD}$ & $277 \pm 277$ & $179 \pm 159$ & $\mathrm{n} . \mathrm{s}$ \\
OP time & $\min \pm \mathrm{SD}$ & $74 \pm 15$ & $83 \pm 14$ & $\mathrm{n} . \mathrm{s}$ \\
ST/G & $n(\%)$ & $4(6)$ & $4(6)$ & $\mathrm{n} . \mathrm{s}$ \\
Additional injury & $n(\%)$ & $41(60)$ & $41(60)$ & $\mathrm{n} . \mathrm{s}$ \\
Medial meniscus & $n(\%)$ & $29(42)$ & $28(40)$ & $\mathrm{n} . \mathrm{s}$ \\
Lateral meniscus & $n(\%)$ & $19(28)$ & $12(17)$ & $\mathrm{n} . \mathrm{s}$ \\
Sutures & $n(\%)$ & $16(24)$ & $20(29)$ & $\mathrm{n} . \mathrm{s}$ \\
Suture medial & $n(\%)$ & $11(16)$ & $12(17)$ & \\
Suture lateral & $n(\%)$ & $5(7)$ & $8(12)$ & \\
Cartilage inj & $n(\%)$ & $7(10)$ & $14(20)$ & $\mathrm{n} . \mathrm{s}$ \\
\hline
\end{tabular}

Reconstruction patient demographics at baseline for patients who underwent ACLR are displayed as mean $\pm \mathrm{SD}$, number and percentage, respectively

$A C L$ anterior cruciate ligament

\section{Patient-related outcome}

As shown in Table 4 and Fig. 2, no difference in patientrelated outcome scores were found. Lysholm [28], KOOS [19], IKDC [10], and Tegner [28] showed no statistically significant differences between the groups.

\section{Functional recovery (FR), Patient acceptable symptom state (PASS) and treatment failure (TF)}

FR is defined as a Knee Osteoarthritis Outcome Score (KOOS) above: 90 for Pain, 84 for Symptoms, 91 ADL, 80 for Sport/Rec and 81 for quality of life (QoL), while the PASS thresholds for IKDC score is above 75.9 and for KOOS they are 88.9 for Pain, 57.1 for Symptoms, 100.0 for ADL, 75.0 for the Sport/Rec, and 62.5 for QoL [7, 18]. $\mathrm{TF}$ is defined as a KOOS, QoL $<44$ [7]. No significant differences between the groups were found Table 4 . 
Table 4 Patient-reported outcomes

\begin{tabular}{|c|c|c|c|}
\hline & Ipsilateral ACLR & $\begin{array}{l}\text { Contralateral } \\
\text { ACLR }\end{array}$ & $p$-value \\
\hline \multicolumn{4}{|c|}{ Patient-reported outcomes at } \\
\hline \multicolumn{4}{|c|}{ Lysholm mean $(\mathrm{SD})^{\mathrm{a}}$} \\
\hline $\begin{array}{l}\text { Inclusion } \\
\quad(n=64 / 65)\end{array}$ & $59(16)$ & $59(14)$ & n.s \\
\hline $\begin{array}{l}6 \text { months } \\
\quad(n=61 / 62)\end{array}$ & $71(15)$ & $67(15)$ & n.s \\
\hline $\begin{array}{l}12 \text { months } \\
(n=53 / 56)\end{array}$ & $74(16)$ & $76(14)$ & n.s \\
\hline $\begin{array}{l}24 \text { months } \\
\quad(n=53 / 64)\end{array}$ & $79(20)$ & $82(15)$ & n.s \\
\hline \multicolumn{4}{|c|}{ Tegner median (range) ${ }^{\mathrm{b}}$} \\
\hline Before injury & $7(2-10)$ & $8(4-10)$ & n.s \\
\hline Inclusion & $2(0-7)$ & $2(0-9)$ & n.s \\
\hline 6 months & $4(0-10)$ & $4(0-8)$ & n.s \\
\hline 12 months & $5(0-10)$ & $5(0-9)$ & n.s \\
\hline 24 months & $5(0-10)$ & $5(2-10)$ & n.s \\
\hline \multicolumn{4}{|l|}{$\operatorname{IKDC}(\mathrm{SD})^{\mathrm{c}}$} \\
\hline $\begin{array}{l}\text { Inclusion } \\
\quad(n=65 / 65)\end{array}$ & $51(16)$ & $52(13)$ & n.s \\
\hline $\begin{array}{l}6 \text { months } \\
\quad(n=61 / 60)\end{array}$ & $60(16)$ & $57(14)$ & n.s \\
\hline $\begin{array}{l}12 \text { months } \\
\quad(n=53 / 56)\end{array}$ & $70(18)$ & $74(15)$ & n.s \\
\hline $\begin{array}{l}24 \text { months } \\
\quad(n=53 / 63)\end{array}$ & $72(19)$ & $75(14)$ & n.s \\
\hline \multicolumn{4}{|l|}{$\mathrm{FR} n(\%)^{\mathrm{d}}$} \\
\hline 24 months & $13(19)$ & $9(13)$ & n.s \\
\hline \multicolumn{4}{|l|}{$\begin{array}{l}\text { PASS KOOS } n \\
(\%)^{\mathrm{e}}\end{array}$} \\
\hline 24 months & $28(52)$ & $39(61)$ & n.s \\
\hline \multicolumn{4}{|c|}{ PASS IKDC $n(\%)^{\mathrm{f}}$} \\
\hline 24 months & $28(52)$ & $30(48)$ & n.s \\
\hline \multicolumn{4}{|l|}{$\mathrm{TF} n(\%)^{\mathrm{g}}$} \\
\hline 24 months & $8(11)$ & $8(11)$ & n.s \\
\hline
\end{tabular}

$A C L$ anterior cruciate ligament, $C L$ uninjured contralateral limb

${ }^{a}$ Score range from 0 to 100 , with higher scores indicating better results

${ }^{\mathrm{b}}$ Assesses activity level with specific emphasis on knee; scores range from 1 (least strenuous activity) to 10 (high knee demanding activity on professional sports level)

${ }^{\mathrm{c}}$ Score range from 0 to 100 , with higher scores indicating better results

${ }^{\mathrm{d}}$ Defined as knee osteoarthritis outcome score (KOOS) above: 90 for pain, 84 for symptoms, 91 for ADL, 80 for Sport/Rec and 81 for quality of life (QoL)

edefined as Knee Osteoarthritis Outcome Score (KOOS) above 88.9 for Pain, 57.1 for Symptoms, 100.0 for ADL, 75.0 for the Sport/Rec, and 62.5 for QoL

${ }^{\mathrm{f}}$ Defined as IKDC score $>75.9$

${ }^{\mathrm{g}}$ Defined as KOOS, QoL $<44$

\section{Objective measures}

ROM as well as manual laxity measurements did not demonstrate any significant differences between the IL and CL surgery patients, Table 5 .

Similar results were found in the groups regarding muscle circumference and functional strength measured with the one-leg hop test.

\section{Functional strength}

The CL group demonstrated significantly stronger isometric extension muscle strength at both 6 and 12 months, but not at 24 months.

Regarding isokinetic flexion muscle strength and total work in flexion, the IL group were significantly weaker in all velocities during the trial period.

There were no statistically significant differences in any other strength assessments, although higher values were found for the CL group, Figs. 3, 4, 5, 6, 7.

\section{Additional surgery}

Additional surgery was required in nine cases (13\%) in the IL group and 15 (21\%) in the CL group (n.s.), Table 6. Two patients in each group sustained a graft rupture during the study period and both reported a significant new trauma. One patient in the CL group suffered a contralateral ACL rupture.

\section{Discussion}

The most important finding of the present study was that the use of a contralateral ST graft facilitates earlier isokinetic and isometric strength recovery after ACLR.

The results support the hypothesis that the use of a contralateral ST graft in ACLR, in comparison to an ipsilateral ST graft, can improve muscle strength in knee flexion and facilitate early symmetrical strength between limbs. A further finding was that both groups demonstrated improvements in all self-reported and objective assessments up to one-year post surgery. These improvements plateaued from 12 to 24 months, with no significant differences observed between the groups.

This study found a significant deficit in both isometric and isokinetic flexion strength in the limb where the graft was harvested. This reflects the findings of other studies $[5,14,15,31]$ which have shown continued strength deficits more than 2 years post-surgery. In contrast, previous 


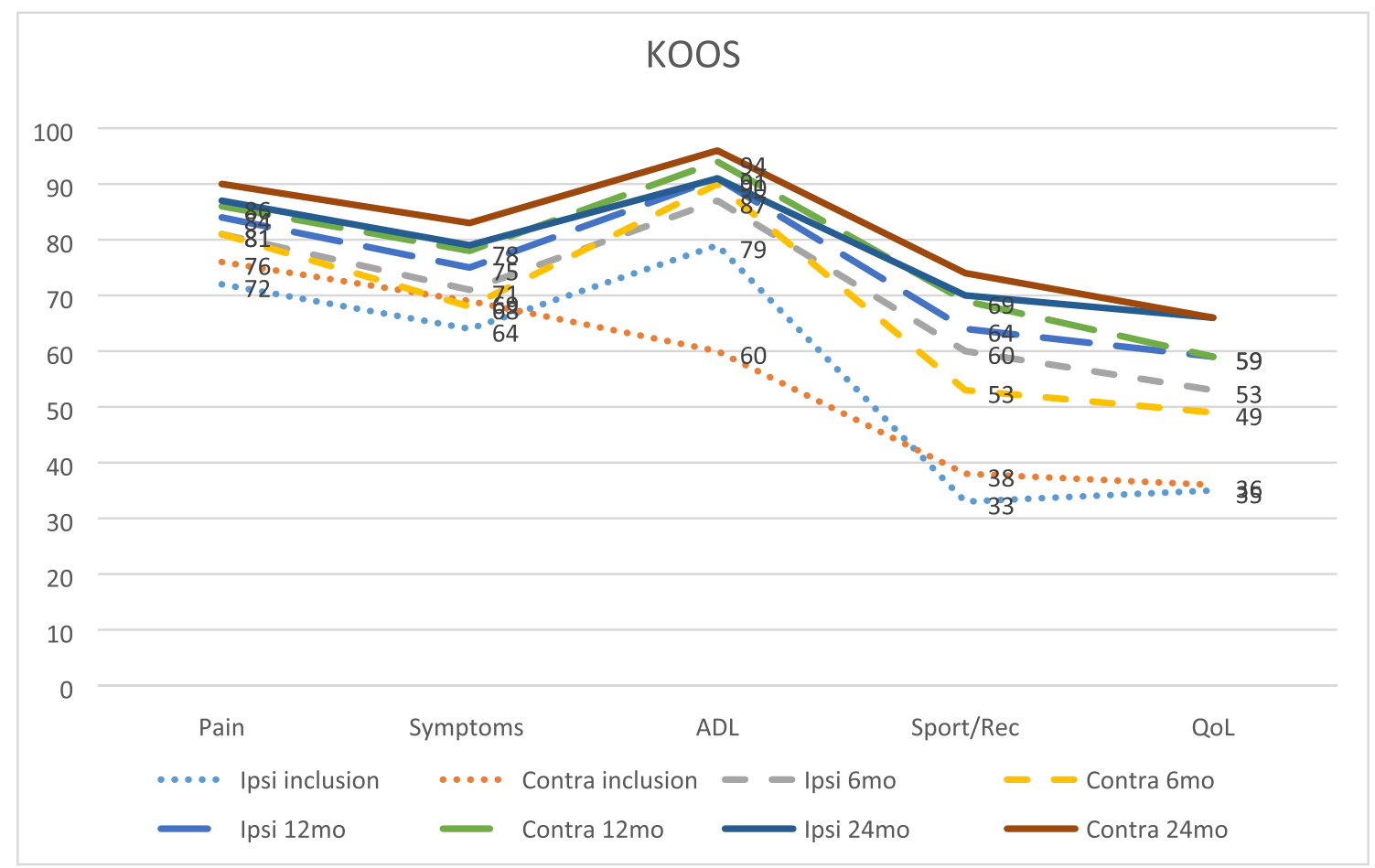

Mean KOOS score

Fig. 2 KOOS. mean KOOS score

studies by Yasuda et al. and McRae et al. [16,33] did not find any long-term differences between limbs.

In this study, symmetrical leg strength was achieved as early as 6 months postoperatively in the CL group, however, in the IL group isokinetic flexion strength remained asymmetrical for the duration of the trial.

There was no difference between the groups with respect to IKDC, Lysholm, KOOS or knee laxity. This is in line with earlier studies by Yasuda and McRae [16, 33]. Tegner level did not return to preinjury level. It is unclear if this was due to knee function or other factors. A contributing factor may have been the mean age of study participants, 33 , an age where family and career commitments may be demanding, potentially resulting in lower activity levels. A further consideration is that although this study was initially designed to only include highly active patients, those with lower demands as well as non-active patients and patients with an unstable knee were also included. This may have contributed to the continued muscle weakness recorded at 24 months follow-up. In a meta-analysis Ardern et al. [4] reported that two-thirds of patients manage to return to their previous activity level and $82 \%$ returned to some type of sport participation. Von Essen et al. [29] reported from the same institute a return to pre-injury at $86 \%$, however, the participants in that study were highly active athletes with a strong desire to return to sport. This study also shows the difference between FR and PASS and why these values are different and not interchangeable. While FR is equal to a return to an almost pre-injury KOOS level, PASS is a measure of what the patient finds in an acceptable state. FR is only half of what Barenius et al. [7] found, while PASS values are in line with other studies $[8,11]$. TF is also only a third of what Barenius et al. found, and in line with Ingelsrud et al. although their cut off was set lower [7, 11]. These patients might not be struggling to get back to highlevel sports, instead they are happy with a functional knee that does not give away.

A theoretical advantage of CL graft harvest is that the ST tendon's contribution to dynamic stabilization is not compromised, hence normal knee biomechanics are better maintained. However, if the contralateral healthy knee develops impaired knee kinematics as a result of graft harvesting, this could also be a potential disadvantage which could increase the risk of injury. Previous studies have found the risk of a contralateral ACL rupture is approximately 3\% [3, 13]. Andernord et al. [3] found in the Swedish national anterior cruciate ligament register that females undergoing ACLR have a 3 times higher risk of ACL rupture on the contralateral side following CL harvest. According to these figures the number of CL ruptures in this study should have been 1.8 (3\%) for the CL group and for the 23 females in CL group the expected numbers should be 1.9(9\%), however, only one was observed. Although not adequately powered to address this issue conclusively, an increased rate of $\mathrm{CL}$ graft ruptures 
Table 5 Objective measures

\begin{tabular}{|c|c|c|c|}
\hline & Ipsilateral ACLR & Contralateral ACLR & $p$ value \\
\hline \multicolumn{4}{|l|}{ Instrumented knee laxity } \\
\hline \multicolumn{4}{|l|}{ Rolimeter mean mm (SD) } \\
\hline 6 months $(n=42 / 47)$ & $1.3(1.3)$ & $1.3(1.2)$ & n.s \\
\hline 12 months $(n=39 / 41)$ & $1.4(1.5)$ & $2.0(3.1)$ & n.s \\
\hline 24 months $(n=45 / 47)$ & $1.7(1.8)$ & $1.5(1.5)$ & n.s \\
\hline \multicolumn{4}{|l|}{ Range of motion } \\
\hline \multicolumn{4}{|c|}{ Ext. def $>5^{\circ}$ compared to CL $n(\%)$} \\
\hline 6 weeks $(n=70 / 65)$ & $10(14)$ & $5(8)$ & n.s \\
\hline 6 months $(n=46 / 48)$ & $4(8)$ & $7(14)$ & n.s \\
\hline 12 months $(n=42 / 51)$ & $3(7)$ & $7(13)$ & n.s \\
\hline 24 months $(n=48 / 49)$ & $4(8)$ & $4(8)$ & n.s \\
\hline \multicolumn{4}{|c|}{ No (\%) normal Pivot Shift test ${ }^{\mathrm{a}}$} \\
\hline 24 months $(n=48 / 50)$ & $43(90)$ & $48(96)$ & n.s \\
\hline \multicolumn{4}{|c|}{ No (\%) normal Lachmann test ${ }^{\mathrm{b}}$} \\
\hline 24 months $(n=48 / 50)$ & $48(100)$ & $49(98)$ & n.s \\
\hline \multicolumn{4}{|l|}{ Functional strength } \\
\hline \multicolumn{4}{|c|}{$\begin{array}{l}\text { Thigh deficit circ. } 10 \mathrm{~cm} \text { above patella } \\
\text { diff in } \mathrm{cm} \text { ref } \mathrm{CL}\end{array}$} \\
\hline 6 months $(n=51 / 53)$ & $1(1)$ & $1(1)$ & n.s \\
\hline 12 months $(n=46 / 51)$ & $1(1)$ & $0(1)$ & 0.04 \\
\hline 24 months $(n=48 / 50)$ & $0(1)$ & $0(1)$ & n.s \\
\hline \multicolumn{4}{|l|}{ One leg hop $n(\%)^{\mathrm{c}}$} \\
\hline \multicolumn{4}{|l|}{6 months $(n=40 / 44)$} \\
\hline$>90$ & $16(40)$ & $19(43)$ & n.s \\
\hline $76-89$ & $14(35)$ & $12(27)$ & \\
\hline $50-75$ & $6(15)$ & $9(21)$ & \\
\hline$<50$ & $4(10)$ & $4(9)$ & \\
\hline \multicolumn{4}{|l|}{12 months $(n=34 / 47)$} \\
\hline$>90$ & $19(56)$ & $29(62)$ & n.s \\
\hline $76-89$ & $6(18)$ & $14(30)$ & \\
\hline $50-75$ & $5(15)$ & $3(6)$ & \\
\hline$<50$ & $4(12)$ & $1(2)$ & \\
\hline \multicolumn{4}{|l|}{24 months $(n=44 / 46)$} \\
\hline$>90$ & $27(61)$ & $31(67)$ & n.s \\
\hline $76-89$ & $14(32)$ & $9(20)$ & \\
\hline $50-75$ & $3(7)$ & $2(4)$ & \\
\hline$<50$ & 0 & $4(9)$ & \\
\hline
\end{tabular}

$A C L R$ anterior cruciate ligament reconstruction, $C L$ contralateral limb

${ }^{a}$ Assesses rotational stability of knee at rest result range from 0 (normal stability) to 3 (severely increased instability)

${ }^{\mathrm{b}}$ Assesses rotational stability of knee at rest result range from 0 (normal stability) to 3 (severely increased instability)

${ }^{c}$ Result indicates if the patient is ready to return to play, to pass, the involved leg must measure at least $90 \%$ of the distance compared to the uninvolved leg

was not apparent in this study, hence CL graft harvest does not appear to increase the risk of reinjuries or ruptures of the contralateral ACL. A longer follow-up period would allow us to better evaluate this risk.

The major strength of this study is the prospective, randomized design with two experienced orthopedic surgeons performing the ACLR with the same standardized technique. The groups were comparable in terms of age, gender and additional injuries and both subjective and objective measurements were made.

There are, however, limitations for this study. Firstly, rehabilitation was not made at the same center and there 


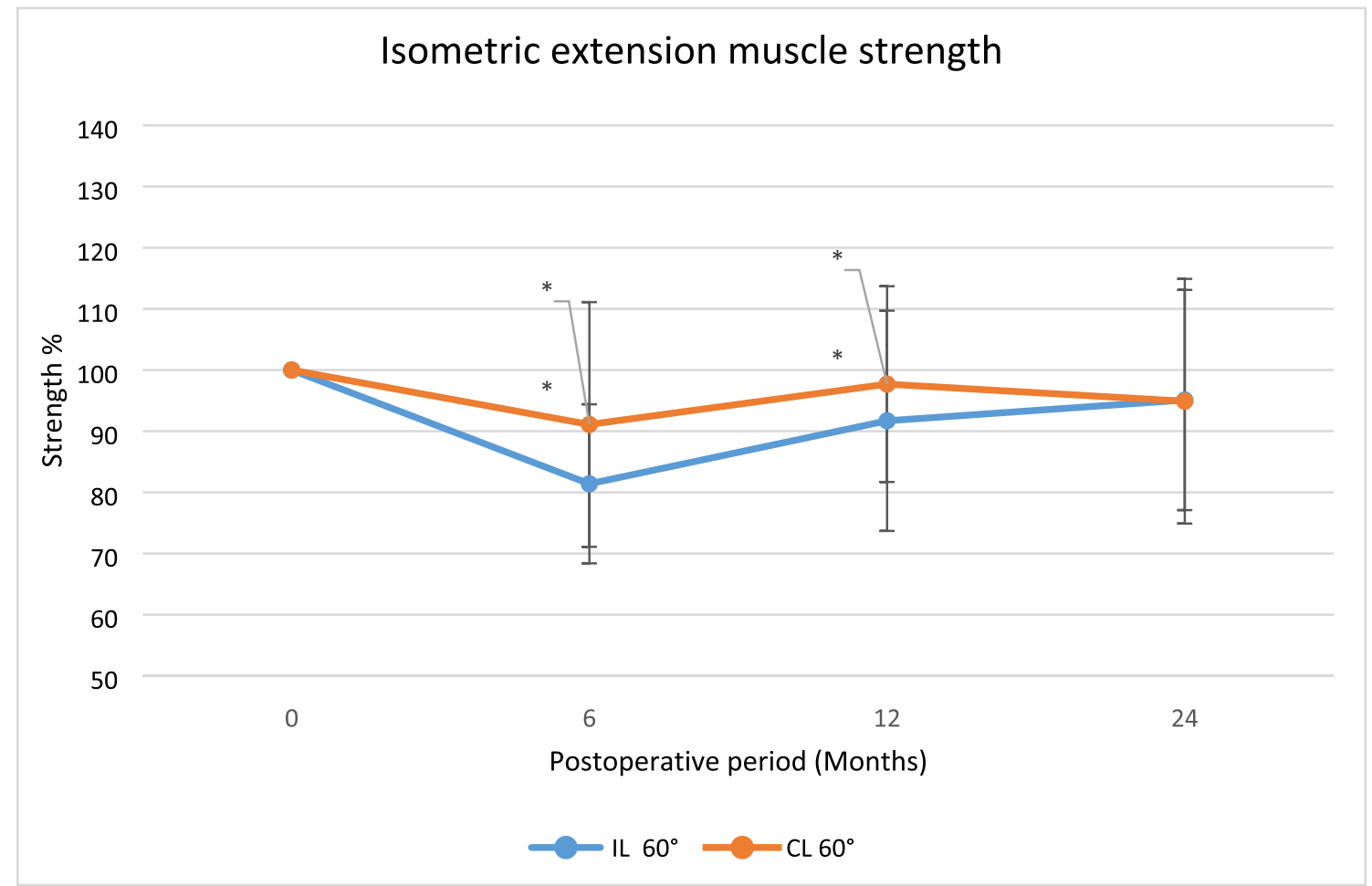

Fig. 3 The average isometric extension muscle strength after surgery displayed as mean percentage with reference contralateral leg set at $100,{ }^{*} p<0.05$

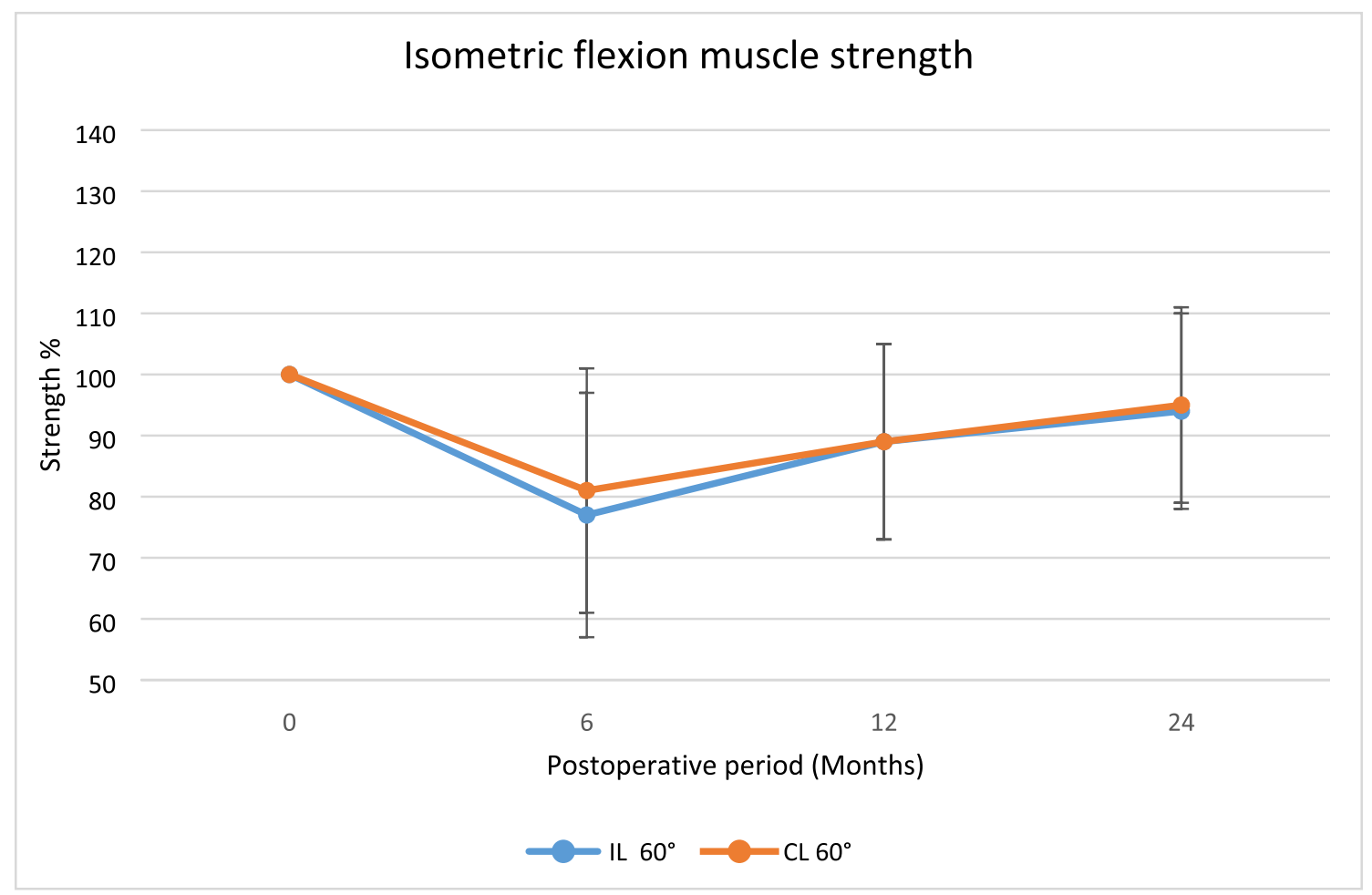

Fig. 4 The average isometric lexion muscle strength after surgery displayed as mean percentage with reference contralateral leg set at 100 , $* p<0.05$ 


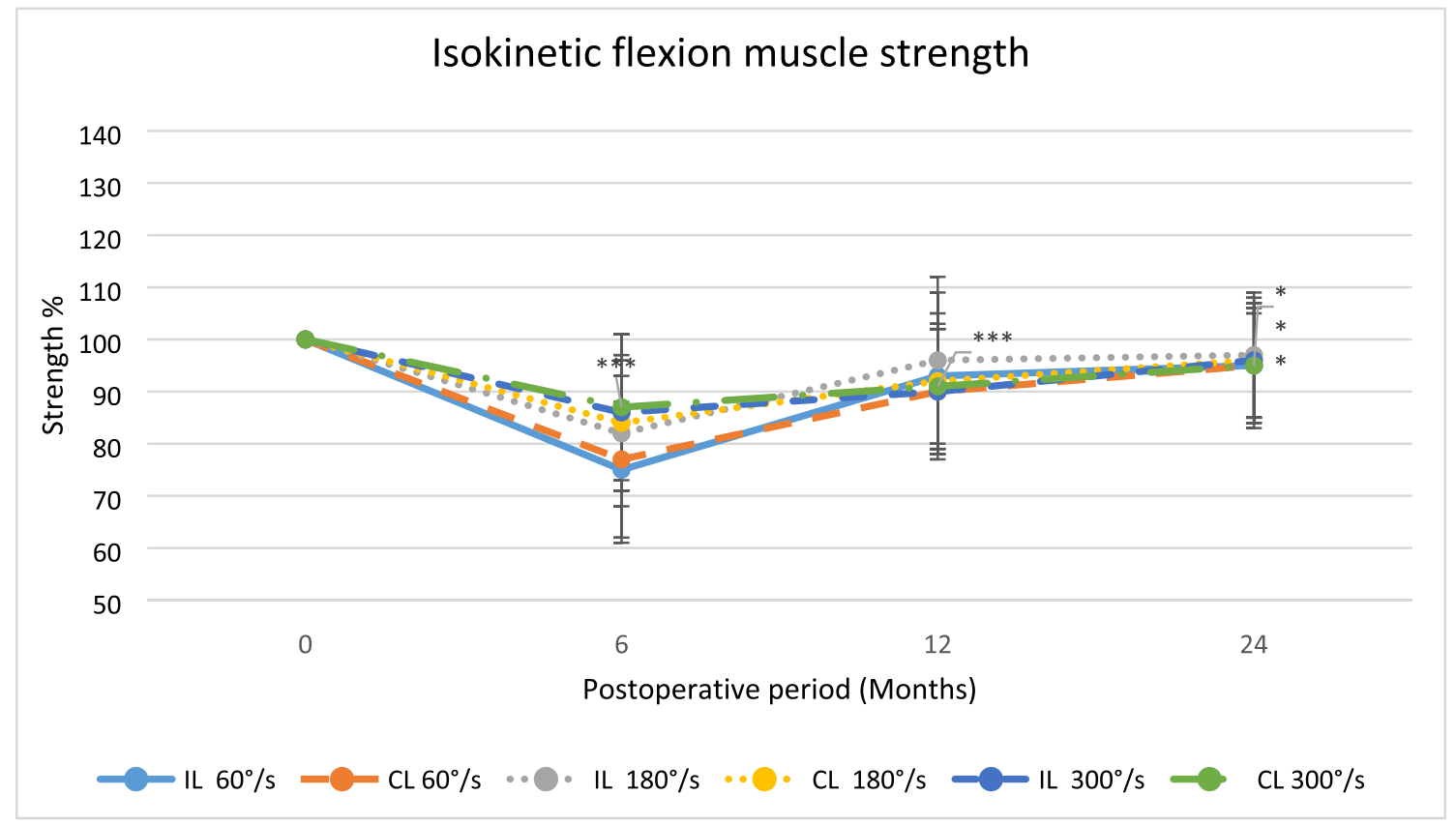

Fig. 5 The average isokinetic flexion muscle strength after surgery displayed as mean percentage with reference contralateral leg set at $100,{ }^{*} p<0.05$

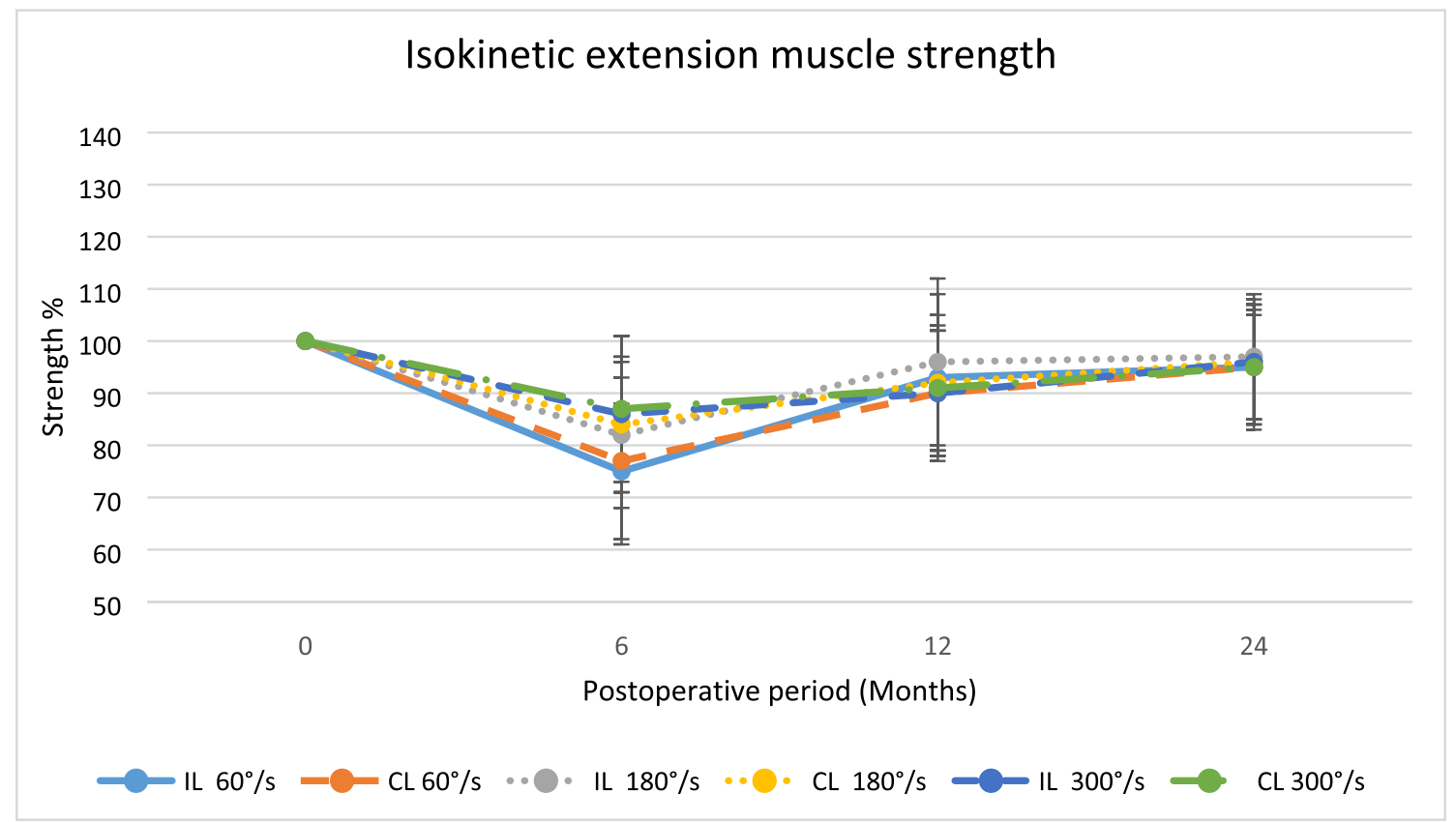

Fig. 6 The average isokinetic ext. muscle strength after surgery displayed as mean percentage with reference contralateral leg set at 100 , $* p<0.05$

was no measurement of compliance to the standardized rehabilitation protocol that was provided.

Another weakness of this study was a loss to follow-up. It was anticipated some loss to follow up and therefore enrolled 140 patients instead of the stipulated 94, which would have been sufficient with a $20 \%$ loss to follow up, however, this figure was exceeded with regard to some evaluations. The smaller sample size may have reduced the power of the study, however, an adequate number of patients were nonetheless analyzed according to the pre-study power analysis. 


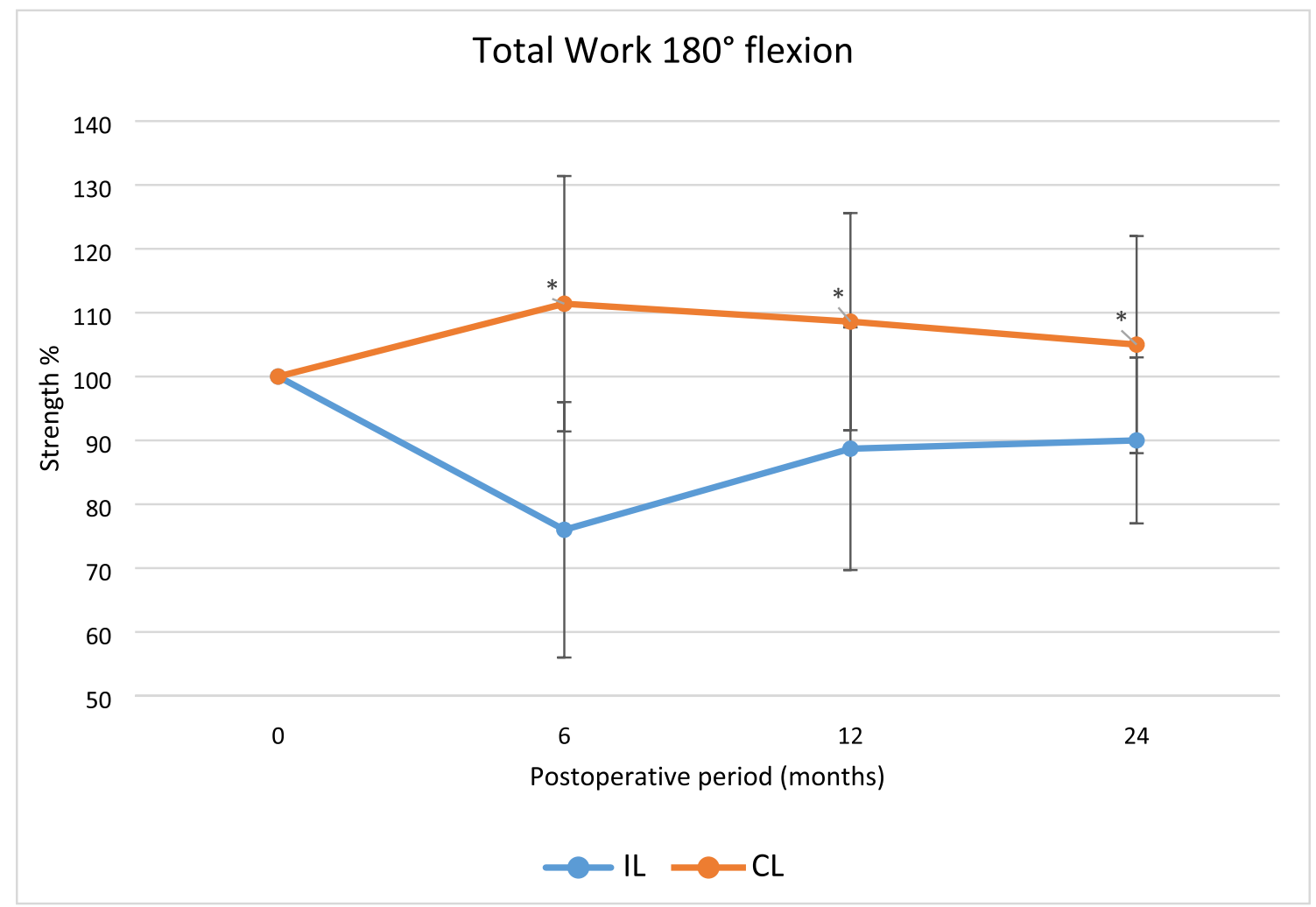

Fig. 7 The average total work at $180 \%$ s after surgery displayed as mean percentage with reference contralateral leg set at $100, * p<0.05$

\section{Conclusion}

This study demonstrates that utilizing a ST graft harvested from the uninjured limb for ACLR facilitates early isokinetic and isometric strength recovery, with no significant adverse outcomes demonstrated in other measurements and therefore be performed to reduce the risk of long-term strength deficits in the injured leg.

Table 6 Additional surgery

\begin{tabular}{llll}
\hline & $\begin{array}{l}\text { Ipsilateral } \\
\text { ACLR } \\
(n=68)\end{array}$ & $\begin{array}{l}\text { Contralat- } \\
\text { eral ACLR } \\
(n=68)\end{array}$ & $p$ value \\
\hline $\begin{array}{l}\text { Additional surgery within } \\
24 \text { months, } n \text { patients }(\%)\end{array}$ & $9(13)$ & $15(21)$ & n.s \\
Reason for reoperation $n(\%)$ & & & \\
Cyclops lesion & $4(6)$ & $8(11)$ & \\
Graft rupture & $2(3)$ & $2(3)$ & \\
Endobutton removal & 0 & $1(1)$ & \\
Contralateral ACLR & 0 & $1(1)$ & \\
Meniscal lesion & $1(1)$ & $3(4)$ & \\
Infection & $2(3)$ & 0 & \\
\hline
\end{tabular}

Funding Open access funding provided by Karolinska Institute.

Open Access This article is licensed under a Creative Commons Attribution 4.0 International License, which permits use, sharing, adaptation, distribution and reproduction in any medium or format, as long as you give appropriate credit to the original author(s) and the source, provide a link to the Creative Commons licence, and indicate if changes were made. The images or other third party material in this article are included in the article's Creative Commons licence, unless indicated otherwise in a credit line to the material. If material is not included in the article's Creative Commons licence and your intended use is not permitted by statutory regulation or exceeds the permitted use, you will need to obtain permission directly from the copyright holder. To view a copy of this licence, visit http://creativecommons.org/licenses/by/4.0/.

\section{References}

1. Aglietti P, Giron F, Buzzi R, Biddau F, Sasso F (2004) Anterior cruciate ligament reconstruction: bone-patellar tendon-bone compared with double semitendinosus and gracilis tendon grafts. A prospective, randomized clinical trial. J Bone Joint Surg Am 86:2143-2155

2. Ahlden M, Samuelsson K, Sernert N, Forssblad M, Karlsson J, Kartus J (2012) The Swedish National Anterior Cruciate Ligament Register: a report on baseline variables and outcomes of surgery for almost 18,000 patients. Am J Sports Med 40:2230-2235

3. Andernord D, Desai N, Björnsson H, Gillén S, Karlsson J, Samuelsson K (2015) Predictors of contralateral anterior cruciate 
ligament reconstruction: a cohort study of 9061 patients with 5-year follow-up. Am J Sports Med 43:295-302

4. Ardern CL, Webster KE, Taylor NF, Feller JA (2011) Return to sport following anterior cruciate ligament reconstruction surgery: a systematic review and meta-analysis of the state of play. Br J Sports Med 45:596-606

5. Aune AK, Holm I, Risberg MA, Jensen HK, Steen H (2001) Four-strand hamstring tendon autograft compared with patellar tendon-bone autograft for anterior cruciate ligament reconstruction. A randomized study with two-year follow-up. Am J Sports Med 29:722-728

6. Balasch H, Schiller M, Friebel H, Hoffmann F (1999) Evaluation of anterior knee joint instability with the Rolimeter. A test in comparison with manual assessment and measuring with the KT-1000 arthrometer. Knee Surg Sports Traumatol Arthrosc 7:204-208

7. Barenius B, Forssblad M, Engstrom B, Eriksson K (2013) Functional recovery after anterior cruciate ligament reconstruction, a study of health-related quality of life based on the Swedish National Knee Ligament Register. Knee Surg Sports Traumatol Arthrosc 21:914-927

8. Cristiani R, Mikkelsen C, Edman G, Forssblad M, Engström B, Stålman A (2020) Age, gender, quadriceps strength and hop test performance are the most important factors affecting the achievement of a patient-acceptable symptom state after ACL reconstruction. Knee Surg Sports Traumatol Arthrosc 28:369-380

9. Fischer F, Fink C, Herbst E, Hoser C, Hepperger C, Blank C et al (2018) Higher hamstring-to-quadriceps isokinetic strength ratio during the first post-operative months in patients with quadriceps tendon compared to hamstring tendon graft following ACL reconstruction. Knee Surg Sports Traumatol Arthrosc 26:418-425

10. Hefti F, Müller W, Jakob RP, Stäubli HU (1993) Evaluation of knee ligament injuries with the IKDC form. Knee Surg Sports Traumatol Arthrosc 1:226-234

11. Ingelsrud LH, Granan LP, Terwee CB, Engebretsen L, Roos EM (2015) Proportion of patients reporting acceptable symptoms or treatment failure and their associated KOOS values at 6 to 24 months after anterior cruciate ligament reconstruction: a study from the Norwegian Knee Ligament Registry. Am J Sports Med 43:1902-1907

12. Janssen RP, van der Velden MJ, Pasmans HL, Sala HA (2013) Regeneration of hamstring tendons after anterior cruciate ligament reconstruction. Knee Surg Sports Traumatol Arthrosc 21:898-905

13. Kaeding CC, Pedroza AD, Reinke EK, Huston LJ, Spindler KP (2015) Risk factors and predictors of subsequent acl injury in either knee after ACL reconstruction: prospective analysis of 2488 primary ACL reconstructions from the MOON cohort. Am J Sports Med 43:1583-1590

14. Lautamies R, Harilainen A, Kettunen J, Sandelin J, Kujala UM (2008) Isokinetic quadriceps and hamstring muscle strength and knee function 5 years after anterior cruciate ligament reconstruction: comparison between bone-patellar tendon-bone and hamstring tendon autografts. Knee Surg Sports Traumatol Arthrosc 16:1009-1016

15. Maletis GB, Cameron SL, Tengan JJ, Burchette RJ (2007) A prospective randomized study of anterior cruciate ligament reconstruction: a comparison of patellar tendon and quadruple-strand semitendinosus/gracilis tendons fixed with bioabsorbable interference screws. Am J Sports Med 35:384-394

16. McRae S, Leiter J, McCormack R, Old J, MacDonald P (2013) Ipsilateral versus contralateral hamstring grafts in anterior cruciate ligament reconstruction: a prospective randomized trial. Am J Sports Med 41:2492-2499

17. Mouarbes D, Menetrey J, Marot V, Courtot L, Berard E, Cavaignac E (2019) Anterior cruciate ligament reconstruction: a systematic review and meta-analysis of outcomes for quadriceps tendon autograft versus bone-patellar tendon-bone and hamstring-tendon autografts. Am J Sports Med 47:3531-3540
18. Muller B, Yabroudi MA, Lynch A, Lai CL, van Dijk CN, Fu FH et al (2016) Defining thresholds for the patient acceptable symptom state for the IKDC subjective knee form and KOOS for patients who underwent ACL reconstruction. Am J Sports Med 44:2820-2826

19. Roos EM, Roos HP, Ekdahl C, Lohmander LS (1998) Knee injury and osteoarthritis outcome score (KOOS) - validation of a Swedish version. Scand J Med Sci Sports 8:439-448

20. Sajovic M, Stropnik D, Skaza K (2018) Long-term comparison of semitendinosus and gracilis tendon versus patellar tendon autografts for anterior cruciate ligament reconstruction: a 17-year follow-up of a randomized controlled trial. Am J Sports Med 46:1800-1808

21. Sajovic M, Vengust V, Komadina R, Tavcar R, Skaza K (2006) A prospective, randomized comparison of semitendinosus and gracilis tendon versus patellar tendon autografts for anterior cruciate ligament reconstruction: five-year follow-up. Am J Sports Med 34:1933-1940

22. Sanders TL, Maradit Kremers H, Bryan AJ, Larson DR, Dahm DL, Levy BA et al (2016) Incidence of anterior cruciate ligament tears and reconstruction: a 21-year population-based study. Am J Sports Med 44:1502-1507

23. Sharma A, Flanigan DC, Randall K, Magnussen RA (2016) Does Gracilis preservation matter in anterior cruciate ligament reconstruction? a systematic review. Arthroscopy 32:1165-1173

24. Shelbourne KD, Beck MB, Gray T (2015) Anterior cruciate ligament reconstruction with contralateral autogenous patellar tendon graft: evaluation of donor site strength and subjective results. Am J Sports Med 43:648-653

25. Shelbourne KD, Vanadurongwan B, Gray T (2007) Primary anterior cruciate ligament reconstruction using contralateral patellar tendon autograft. Clin Sports Med 26:549-565

26. Slone HS, Romine SE, Premkumar A, Xerogeanes JW (2015) Quadriceps tendon autograft for anterior cruciate ligament reconstruction: a comprehensive review of current literature and systematic review of clinical results. Arthroscopy 31:541-554

27. Taylor NA, Sanders RH, Howick EI, Stanley SN (1991) Static and dynamic assessment of the Biodex dynamometer. Eur J Appl Physiol Occup Physiol 62:180-188

28. Tegner Y, Lysholm J (1985) Rating systems in the evaluation of knee ligament injuries. Clin Orthop Relat Res 198(2):43-49

29. von Essen C, Eriksson K, Barenius B (2019) Acute ACL reconstruction shows superior clinical results and can be performed safely without an increased risk of developing arthrofibrosis. Knee Surg Sports Traumatol Arthrosc 28:2036-2043

30. Widner M, Dunleavy M, Lynch S (2019) Outcomes following ACL reconstruction based on graft type: are all grafts equivalent? Curr Rev Musculoskelet Med 12:460-465

31. Xergia SA, McClelland JA, Kvist J, Vasiliadis HS, Georgoulis AD (2011) The influence of graft choice on isokinetic muscle strength 4-24 months after anterior cruciate ligament reconstruction. Knee Surg Sports Traumatol Arthrosc 19:768-780

32. Xie X, Liu X, Chen Z, Yu Y, Peng S, Li Q (2015) A meta-analysis of bone-patellar tendon-bone autograft versus four-strand hamstring tendon autograft for anterior cruciate ligament reconstruction. Knee 22:100-110

33. Yasuda K, Tsujino J, Ohkoshi Y, Tanabe Y, Kaneda K (1995) Graft site morbidity with autogenous semitendinosus and gracilis tendons. Am J Sports Med 23:706-714

34. Yosmaoglu HB, Baltaci G, Ozer H, Atay A (2011) Effects of additional gracilis tendon harvest on muscle torque, motor coordination, and knee laxity in ACL reconstruction. Knee Surg Sports Traumatol Arthrosc 19:1287-1292

Publisher's Note Springer Nature remains neutral with regard to jurisdictional claims in published maps and institutional affiliations. 